\title{
HIGH CONDYLAR SHAVE WITH MENISCORHAPHY IN THE TREATMENT OF INTERNAL DERANGEMENT OF TEMPOROMANDIBULAR JOINT. CLINICAL, RADIOGRAPHIC, AND PATIENT-BASED OUTCOMES
}

\author{
Hosam E. Said*
}

\begin{abstract}
Purpose: the aim of this study was to evaluate clinical, radiographic and patient-based outcomes of high condylar shave with meniscorhaphy in the treatment of internal derangement of temporomandibular joint

Patients and methods: Seven patients (5 females and 2 males) with unilateral internal derangement of the temporomandibular joint (TMJ) who did not respond to previous conservative treatment was included in this study. High condylar shave surgery with meniscorhaphy was performed to all participants. Clinical outcomes (Maximum mouth opening, deviation toward affected joint, extent of lateral excursion, TMJ tenderness, and joint sound), and patient-based outcomes (degree of pain, pain effect on life) were evaluated before surgery, 6 months and one year after surgery. MRI outcomes (Position and morphology of the meniscus, and synovial fluid effusion) were evaluated before surgery and one year after surgery.
\end{abstract}

Results: Maximum mouth opening, and lateral movements significantly increased after six months and one year compared to preoperative measurement. Deviation towards the affected joint, TMJ tenderness, joint sounds significantly decreased after six months and one year compared to preoperative measurement. However, there was no significant difference in these outcomes between six months and one year. Disc position and morphology significantly improved, and synovial fluid effusion significantly reduced after one year compared to preoperative measurements. Mean degree of Pain and effect of pain on life significantly decreased at 6 months and one year compared to preoperative measurements. Mean degree of pain decreased significantly from 6 months to one year. However, pain effect on life did not differ significantly between 6 months and one year.

Conclusion: Within the limitation of this study, high condylar shave with meniscorhaphy in an effective treatment of internal derangement of TMJ in cases which did not respond to conservative treatment as it improved clinical, radiographic, and patient-based outcomes.

\footnotetext{
* Lecturer Oral and Maxillofacial Surgery, Faculty of Dentistry, Delta University For Science and Technology
} 


\section{INTRODUCTION}

Temporomandibular disorders

(TMD)

composed of masticatory system disorders that is accompanied by joint pain/sound, muscle pain, and limited mandibular functions ${ }^{1}$.Severe cases of TMD are associated with reduced quality of life ${ }^{2,3}$. Internal derangement (ID) is an abnormal relationship of the temporomandibular disc to the condyle, glenoid fossa, and articular eminence ${ }^{4}$. ID is the most common TMD disorder (70\% of cases $)^{5}$ and characterized by anterior or anteromedial displacement of the articular $\operatorname{disc}^{6,7}$. Many patients with ID may be treated successfully with conservative approaches as occlusal splints, physiotherapy and medication. However, patients who do not respond to these measures are referred for surgical correction ${ }^{6}$. Several studies reported that the incidence of surgical treatment of ID ranged from $1 \%$ to $25 \%^{8-10}$. The patient should be treated initially by minimal invasive techniques ${ }^{11}$, and when severe symptoms remain after conservative treatment, Temporomandibular joint (TMJ) surgery is indicated ${ }^{12}$.

One principle in treating ID is to increase the joint space, thereby decompressing the joint and presumably increasing joint translation ${ }^{13}$. The treatment of ID may be performed using noninvasive techniques such as (medications, physiotherapy, psychotherapy, prosthetic therapy, and orthodontic therapy), minimally invasive techniques such as (arthroscopy, arthrocentesis) and invasive techniques such as (disk repair and disk repositioning procedures (discopexy, meniscorhaphy), menisectomy with or without autogenous implants, condylectomy, condylotomy, condyloplasty (high condylar shave), disc plication and eminectomy ${ }^{12}$. The high condylar shave and eminectomy aimed to increase the joint space without altering the position of the disc. The disc plication allow the disc to regain its normal position $^{6}$. It has been reported that combinations of more than one surgical procedure is more effective than a single procedure ${ }^{13}$
In a systematic review and meta-analysis, AlMoraiss $\mathrm{i}^{14}$ concluded that open TMJ surgery has superior results compared to arthroscopy in reducing pain for subjects with internal derangement (ID) (disk displacement with reduction), with comparable maximal mouth opening, mandibular movements, and joint sounds/tenderness. However, for subjects with disk displacement without reduction, there is a little evidence regarding the validity of noninvasive or invasive techniques in reducing pain and symptoms $^{11,15}$

One of the classical surgical treatments of the ID is high condylar shave (Walker repair). The technique includes high condyloplasty (removal 2-4 $\mathrm{mm}$ of the superior surface of the condylar head and disc repositioning over the trimmed condyle to provide space for the articular disc between the condyle and temporal fossa, give freedom of joint movement, eliminate pain by preventing compression of the bilaminar zone $e^{4}$. This technique is a modification of high condylectomy. The soft tissue cover of the condyle in the original technique was required, however, preservation of this cover was described later as a modification of the technique ${ }^{16}$. Another surgical technique is meniscoplasty which involves excision and tightening of a portion of the posterior attachment, and reposition the disc ${ }^{5}$. A simple and effective technique that avoids the difficulty of meniscoplasty in disc repositioning is meniscoraphy. The technique consists direct suturing of the fibrous disk to the lateral wall of the capsule ${ }^{17}$.

Reviewing the literature, the effect of high condylar shave in treatment of ID was extensively investigated. However, the effect of combination of high condylar shave and meniscoraphy in treatment of ID was not sufficiently investigated. Accordingly, the aim of this prospective study was to evaluate clinical, radiographic, and patient-based outcomes of high condylar shave with meniscoraphy in the treatment of internal derangement of temporomandibular joint. 


\section{PATIENTS AND METHOD}

\section{Patient selection}

A convenient sample of 7 patients (5 females and 2 males, age ranged from 21 to 46 years) were selected for this prospective study from the outpatient clinic of Oral and Maxillofacial Surgery Department, Faculty of Oral and Dental Medicine, Delta university. The included patients had the following criteria: 1) all patients had unilateral internal derangement (ID) of the temporomandibular joint (TMJ) and anterior disc displacement with, or without reduction. This was diagnosed by Preoperative magnetic resonance imaging (MRI), and clinical examination, and considered the cause of their pain, and disability following exclusion of all other forms of temporomandibular joint disorders (TMD), 2) all patients had one or more classical signs and/or symptoms of ID as pain, tenderness, clicking sounds, limitation of mandibular movement, and chewing disability persisted over at least 3 months prior to diagnosis, 3) Failure of previous conservative treatment to adequately control the symptoms of the patients and their suffering and all participants were considered candidates for surgical treatment. Exclusion criteria are 1) Any previous TMJ surgery, 2) congenital malformation, 3) tumours and systemic causes (as rheumatoid arthritis). All patients informed about their surgical procedures including possible risk and benefits before obtaining signed informed consent from each patient. The study was approved by the ethical committee of the Faculty of dentistry.

\section{Examination and diagnosis}

For each patient, a complete medical history, chief complaint, and dental history were performed. Also, the presence of previous trauma or harmful habits such as bruxism or clenching was recorded. Moreover, careful clinical examination was made to assess the limit of mouth opening, the range and deviation of mandibular movements, pain and tenderness over the joint area or in temporal, frontal, orbital region of the affected side, neck and shoulder muscles, presence of joint sounds and presence of malocclusion. Furthermore, panoramic radiography, and MRI were performed. All the examined patients fulfilled diagnostic criteria of internal derangement of TMJ as suggested by American Association of Oral and Maxillofacial Surgery in 1984. $(\mathrm{AAOMS})^{18}$, which include: 1) Pain or tenderness in the region of TMJ and muscles of mastication, 2) Severe trismus with maximum painless inter-incisal opening (IIO) less than $30 \mathrm{~mm}, 3$ ) Limitation of the mandibular movement, 4) Deviation of the jaw toward the affected side during opening, 5) Sound during condylar movement (popping, crepitus, or clicking), and 6) Magnetic resonance imaging of TMJ shows evidence of anterior or anteromedial displacement of the meniscus. MRI images were obtained for patients in both closed and maximum painless mouth opening. Disc displacement was determined as the angulation at the junction of the posterior band of the disc and the bilaminar zone assumed from the 12 o'clock position in relation to the condyle. The 12 o'clock position was regarded as the perpendicular line drawn from the midpoint of the condyle along the line connecting the summit of the articular eminence and the post glenoid process. Junctions lying within $10^{\circ} \pm 5^{\circ}$ from the 12 o'clock position were considered normal. Whether the case was reducing or nonreducing was MRI determined by the position of the disc in relation to the condylar head in the open mouth sagittal MRI (Fig1).

\section{Surgical procedures}

The surgical operation was made under general anesthesia. Antiseptic iodine solution* was applied over the skin over joint and in the post auricular area. The external auditory canal was blocked with cotton pledget. Preauricular skin and subcutaneous tissues was infiltrated with local anesthesia** to help

\footnotetext{
* 10\%, Mundidone Betadine: The Nile Co. for Pharmaceutical \& Chemical Industries, A.R.E.

** Mepivacaine, Alexandria Co. Pharmaceuticals \& Chemical Industry, Alexandria, Egypt
} 


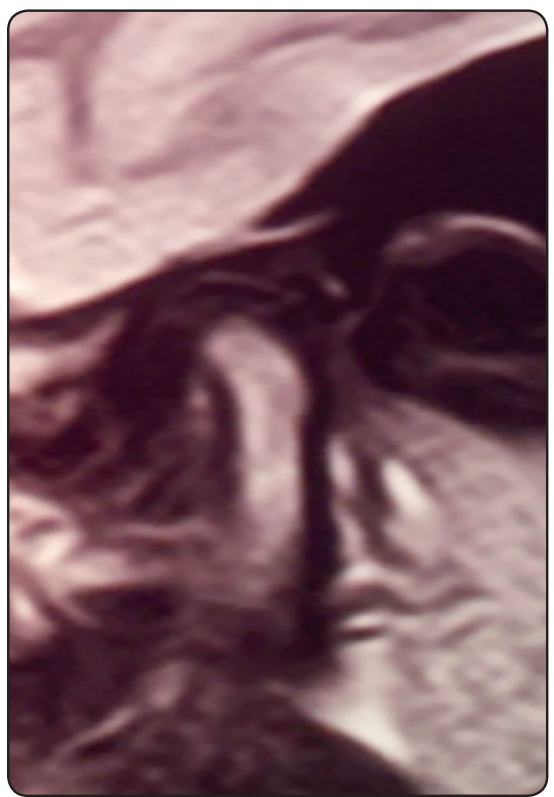

Fig (1) MRI showing severe anterior meniscal displacement with massive synovitis

hemostasis. Endural approach was used for exposure of the TMJ. An incision was started above the level of the zygomatic arch and extended downwards and backwards in the inter cartilaginous cleft between the tragus and the helix. The incision was then made inward along the roof of the auditory meatus for about $1 \mathrm{~cm}$, then continued in the sagittal plane around the anterior half of the meatal circumference at the junction of the cartilaginous and bony canal. The incision should not extend below the lobule of the ear to avoid severance of the main trunk of the facial nerve.

The skin was carefully dissected by artery forceps from the free edges of the ear and retracted anteriorly. The soft tissues attached to the anterior border of the cartilage of the ear was then stripped away with a scalpel so that cartilage will not be cut, the blunt end of the blade is kept against cartilage of ear (Fig2).

In the area immediately anterior to the external auditory tube, the dissection was deepened to the zygomatic temporal fascia. The soft tissues including the superior pole of the parotid gland, the temporal artery, Facial vein, and branches of

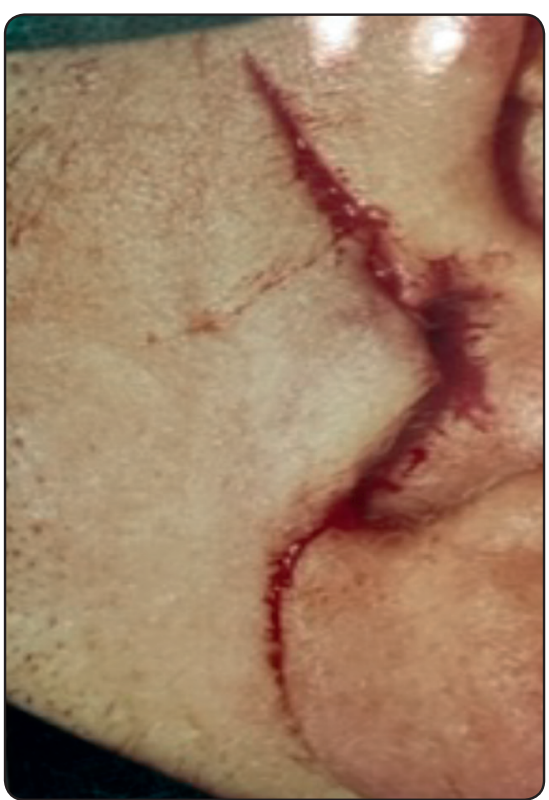

Fig. (2) Endural incision was used to gain access to TMJ

facial nerve were retracted anteriorly as a whole. This anterior dissection exposed the zyomatic arch, the superior lateral roof of the glenoid fossa and the capsule. The temporal fascia and muscles attached to the zygoma were incised to reach the periosteum. The periosteum over the root of zygoma was incised, the incised periosteum was retracted forward, and proceeding toward the anterior half of the rim of the glenoid fossa occurred. The tissues which lie over the lateral aspect of the capsule and the neck of the condyle were dissected to clear out the (TMJ) Structures. Bleeding was controlled by electrocautery for small vessels, and clamping, division, and ligation for large vessels (fig 3).

The TMJ capsule was incised with inverted L-shaped incision around its upper and posterior margins which allow immediate access to the condyle but avoided the meniscus. The condyle was exposed by elevating the periosteum anteriorly, posteriorly, and then superiorly from the lateral pole of the condyle (fig 4).

With the mandible in centric occlusion, the superior articular surface of the condyle was excised using a No.3 round or flat fissure bur attached to 


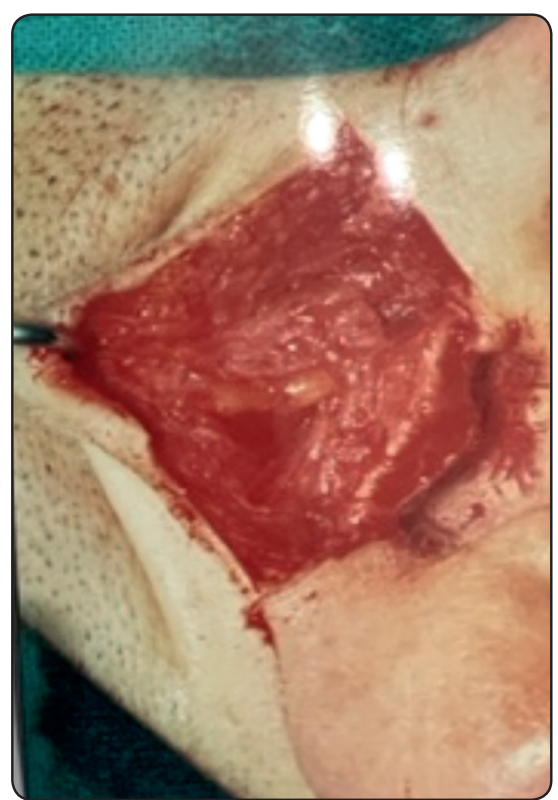

Fig. (3) Dissection of tissues in layers until reach TMJ capsule which is seen

straight low speed hand piece under copious saline irrigation (high condylar shave ${ }^{5,19}$ ). The excision was made obliquely without inwards (from outer cortical plate deep to the spongiosa) so that a wedge greater on the lateral aspect than the medial was removed from the condylar head. The depth of the cut was completed with gentle blows by mallet and an osteotome (bi-beveled chisel). The thickness of the excised bone was $3-5 \mathrm{~mm}$. The fragment was removed with a Kocker forceps after excision of few strands of superior head of lateral pterygoid muscle (fig 5).

The condylar stump was smoothened with round bur then bone file. The disk was mobilized posteriorly into its normal position. The lateral border of the disk was then secured to the retrodiscal connective tissues and to the lateral aspect of the capsule with approximately five to six synthetic absorbable sutures* that are placed 2 to $3 \mathrm{~mm}$ apart (meniscorhaphy) ${ }^{17}$.

\footnotetext{
* 000, Vicryl, Ethicon, Johnson \& Johnson Company
}

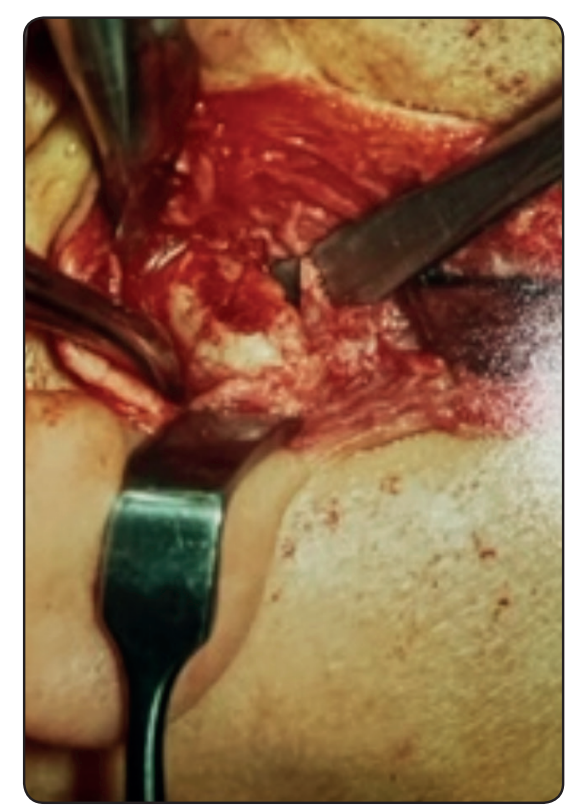

Fig. (4) The condyle is exposed after capsular incision and meniscus is protected to avoid its injury

The surgical wound was irrigated using saline solution, then it was sutured in layers starting by the capsular layer, muscular and subcutaneous layer. No skin suturing was made, only plastic subcuticular

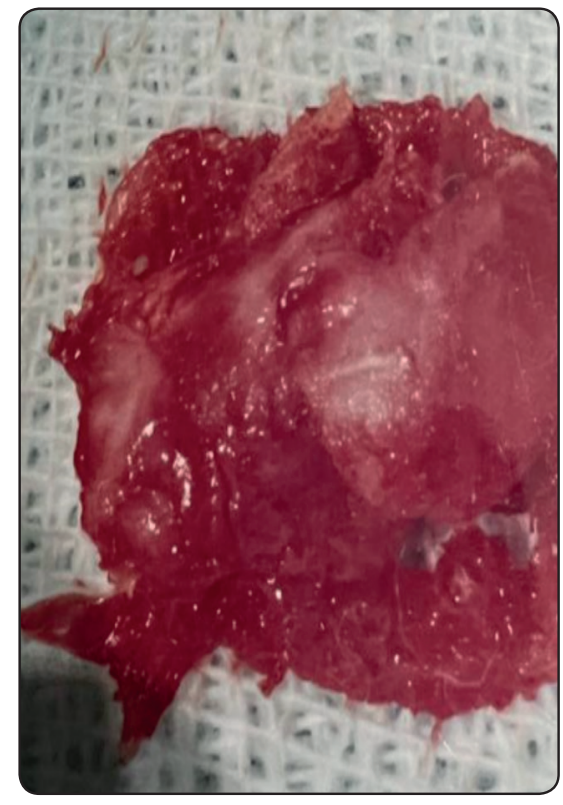

Fig 5. Excision of 3-5 $\mathrm{mm}$ of superior condylar head with strands of superior head of lateral pterygoid muscle 


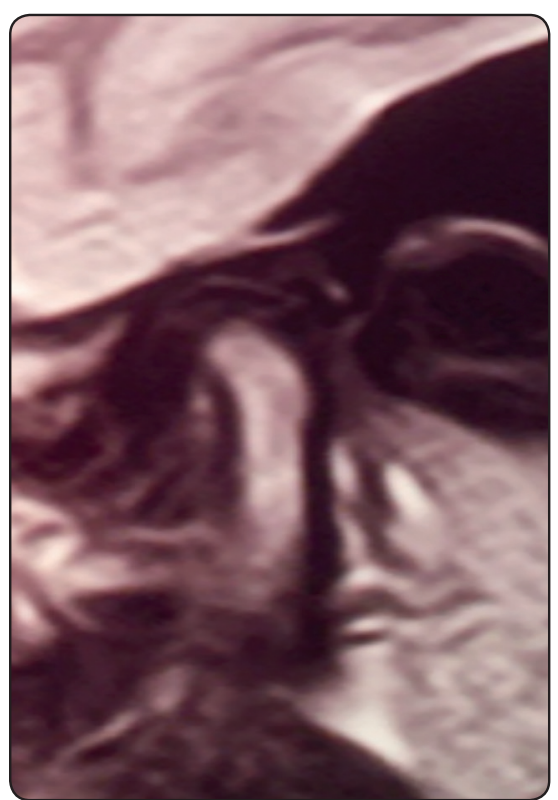

Fig. (6). Subcuticular suturing was the final suturing to surgical site .

suturing was the final suturing to be done using prolene* sutures (fig 6, and fig 7).

Sulbactam /Ampicilline Ampules antibiotics* $1.5 \mathrm{gm}$ was prescribed twice daily for 5 days. Non-steroidal anti-inflammatory and analgesic diclofenac sodium** was prescribed Twice daily for two weeks. Ice packs was applied at the surgical site at the operative day, then hot fomentation was done the next day, and continued for one week. Soft diet was used for 2 weeks post-operatively. Passive motion of the mandible was performed by patient immediately hours post-operative. The patient was encouraged to perform active muscle exercises muscle-stretch (Finger-thumb) exercise, resistive opening and hinge or retruded opening exercise. This was started from the day after the operation for 2 weeks. Suture removal was done after a week.

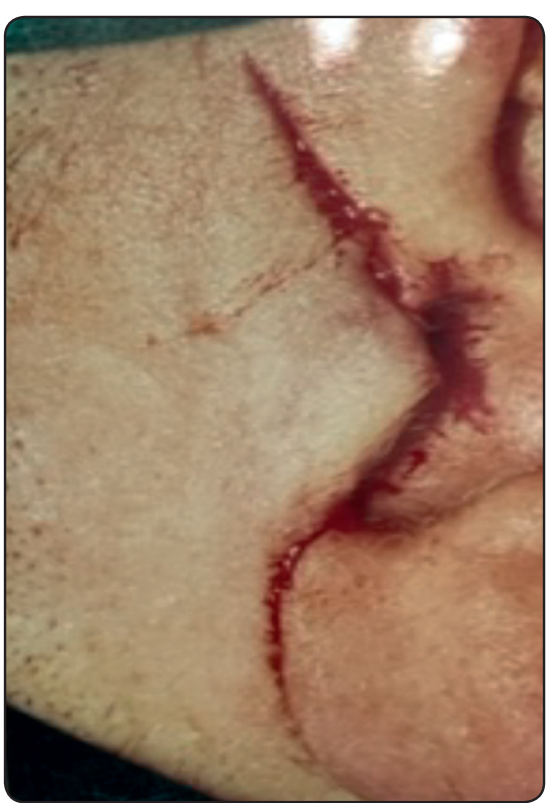

Fig. (7) Minimal scar was seen after complete healing at surgical site

\section{Evaluation of study outcomes}

Clinical and patient-based outcomes were evaluated before surgery, 6 months and one year after surgery. Radiographic outcomes were evaluated one year after surgery.

\section{A) Clinical outcomes}

The following parameters were evaluated

1. Maximum mouth opening: maximum painless interincisal opening in $\mathrm{mm}$.

2. Deviation of mid mandibular incisor line during mouth opening in $\mathrm{mm}$.

3. Extent of lateral excursion: to the right and to the left in $\mathrm{mm}$.

4. Tenderness on palpation (in static, and during motion)

5. Joint sound (popping, crepitus, clicking or grating)

\footnotetext{
* Ethicon, Johnson \& Johnson Company

** Unasyn Amp: Pfizer Egypt S.A.E. Egypt

***Voltaren 75mg Amp: Pfizer Egypt S.A.E. Egypt
} 


\section{B) Radiographic outcomes (Magnetic Resonance Imaging, MRI)}

The following parameters were evaluated

1. Position of the meniscus.

2. Morphology of the meniscus.

3. Synovial fluid effusion.

\section{C) Patient based outcomes}

The following parameters were evaluated

1. Degree of pain: was evaluated using visual analogue scale (VAS) as the patient is asked to draw a mark (on graduated Linkert from 0 to 100) to represent the degree of his pain.

2. Pain effect on life: was evaluated by selection of one of the following scores; score 0 ; no effect, score 2; slight effect, score 3; moderate effect, score 4; sever effect, and score 5 ; cannot function at all.

\section{Statistical analysis}

Data analysis was performed with SPSS program (SPSS Inc., V. 22, Chicago, IL, USA). The data normality and distribution was verified by Shapiro wilk test. Comparison of scale parameters (maximum mouth opening, lateral movement and VAS) between observation times was made by Repeated measures ANOVA followed by paired t-test for multiple comparisons. Comparison of ordinal parameters (TMJ tenderness, disc position and morphology, and pain effect on life) between observation times was made by Freidman test followed by Wilcoxon signed ranks test for multiple comparisons. Comparison of binary categorical parameters (deviation toward affected joint, TMJ sounds, and synovial fluid) between observation times was made by Cochran's Q test (for more than 2 observation times) and McNamar tests (for only 2 observation times. $\mathrm{P}$ is significant if $<0.05$.

\section{RESULTS}

\section{Clinical outcomes}

Comparison of mean of maximum mouth opening, and lateral movements between observation times is presented in table 1 . There was a significant difference in maximum mouth opening $(\mathrm{p}<.001)$ and lateral movement $(\mathrm{p}<.001)$ between observation times. Maximum mouth opening and lateral movements significantly increased after six months and one year compared to preoperative measurement. Also, maximum mouth opening and lateral movements significantly increased after one year compared to 6 months.

Comparison of frequencies (\%) of deviation towards the affected joint between observation times is presented in table 2 . There was a significant difference in frequencies (\%) of deviation towards the affected joint between observation times ( $\mathrm{p}=.002)$. Deviation towards the affected joint significantly decreased after six months and one year compared to preoperative measurement. However, there was no significant difference in deviation towards the affected joint between six months and one year.

Comparison of frequencies (\%) of TMJ tenderness between observation times is presented in table 3 . There was a significant difference in frequencies (\%) of TMJ tenderness between observation times $(\mathrm{p}=.001)$. TMJ tenderness significantly decreased after six months and one year compared to preoperative measurement. However, there was no significant difference in TMJ tenderness between six months and one year.

Comparison of frequencies (\%) of joint sounds between observation times is presented in table 4 . There was a significant difference in frequencies (\%) of joint sounds between observation times $(\mathrm{p}=.006)$. Joint sounds significantly decreased after six months and one year compared to preoperative measurement. However, there was no significant difference in joint sounds between six months and one year. 


\section{MRI outcomes}

For all cases, MRI was made after one year in $\mathrm{T} 1$ and $\mathrm{T} 2$ weighted images in both open and closed mouth positions. Fig 8 shows MRI T2weighted image in open mouth position for case no 5 postoperatively (A) and preoperatively (B) for comparison. Another example is MRI of case no 3. (Fig 9) in T2 weighted images postoperatively and preoperatively.

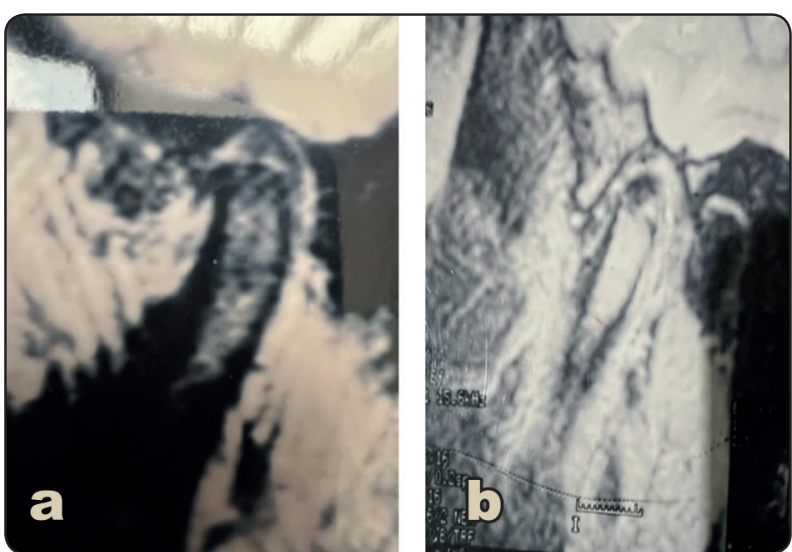

Fig 8. A; MRI T2-weighted image in open mouth position for case no 5 post operatively showing hi-condylar shave, normal position and morphology of the meniscus without synovial effusion, B; The same case preoperatively for comparison.
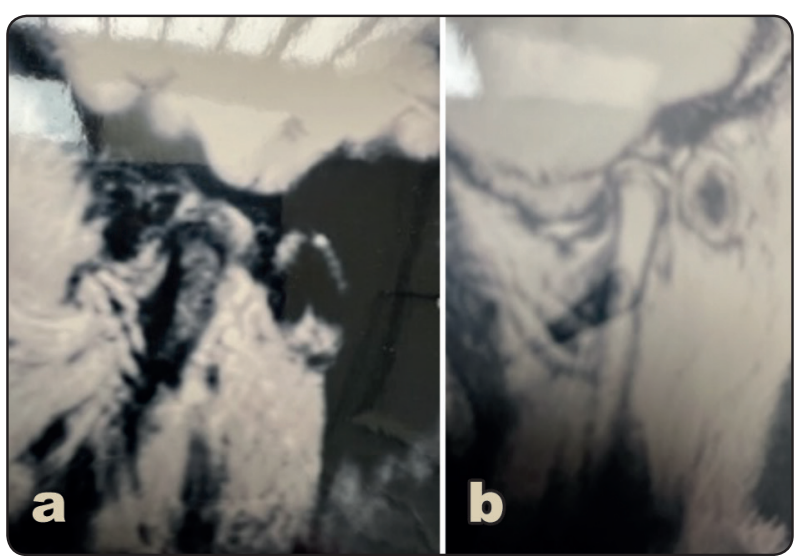

Fig 9. A; MRI T1 and T2 weighted images of case no.3 preoperatively showing increase in joint space, advancement in meniscus position, morphology, and retrodiscal tissues as well synovial fluid change, B) The same case preoperatively for comparison.
TABLE (1) Comparison of mean of maximum mouth opening, and lateral movements between observation times

\begin{tabular}{|c|c|c|c|c|}
\hline & \multicolumn{2}{|c|}{$\begin{array}{c}\text { Maximum } \\
\text { mouth opening }\end{array}$} & \multicolumn{2}{|c|}{$\begin{array}{c}\text { Lateral } \\
\text { movement }\end{array}$} \\
\hline & $\mathrm{X}$ & $\mathrm{SD}$ & $\mathrm{X}$ & SD \\
\hline Pre-operative & 22.43 & 1.51 & 2.14 & 1.07 \\
\hline 6 months & 45.43 & 1.72 & 8.00 & 1.29 \\
\hline 1 year & 50.14 & 1.35 & 11.00 & 1.29 \\
\hline $\begin{array}{c}\text { Repeated measures } \\
\text { ANOVA }\end{array}$ & \multicolumn{2}{|c|}{$<.001 *$} & \multicolumn{2}{|c|}{$<.001 *$} \\
\hline Pre- $6 \mathrm{~m}$ & \multicolumn{2}{|c|}{$<.001 *$} & \multicolumn{2}{|c|}{$.001 *$} \\
\hline Pre -1 y & \multicolumn{2}{|c|}{$<.001 *$} & \multicolumn{2}{|c|}{$<.001 *$} \\
\hline $6 m-1 y$ & \multicolumn{2}{|c|}{$.001 *$} & \multicolumn{2}{|c|}{$.020 *$} \\
\hline
\end{tabular}

*p is significant at $5 \%$

TABLE (2) Comparison of frequencies (\%) of deviation towards the affected joint between observation times

\begin{tabular}{|c|c|c|c|}
\hline & & Frequency & Percentage \\
\hline \multirow[t]{2}{*}{ Pre-operative } & No deviation & 0 & $0 \%$ \\
\hline & deviation & 7 & $100 \%$ \\
\hline \multirow[t]{2}{*}{6 months } & No deviation & 6 & $85.7 \%$ \\
\hline & deviation & 1 & $14.3 \%$ \\
\hline \multirow[t]{2}{*}{1 year } & No deviation & 6 & $85.7 \%$ \\
\hline & deviation & 1 & $14.3 \%$ \\
\hline Cochran's Q test & & $.002 *$ & \\
\hline Pre $-6 m$ & & $<0.008^{*}$ & \\
\hline Pre - 1 y & & $<0.008 *$ & \\
\hline $6 m-1 y$ & & 1.00 & \\
\hline
\end{tabular}

*p is significant at 5\% 
TABLE (3) Comparison of frequencies (\%) of TMJ tenderness between observation times

\begin{tabular}{|c|c|c|c|}
\hline & & Frequency & Percentage \\
\hline \multirow{2}{*}{$\begin{array}{c}\text { Pre- } \\
\text { operative }\end{array}$} & Moderate & 1 & $14.3 \%$ \\
\hline & Severe & 6 & $85.7 \%$ \\
\hline \multirow[t]{3}{*}{6 months } & No & 5 & $71.4 \%$ \\
\hline & Mild & 1 & $14.3 \%$ \\
\hline & Moderate & 1 & $14.3 \%$ \\
\hline \multirow[t]{2}{*}{1 year } & No & 6 & $85.7 \%$ \\
\hline & Mild & 1 & $14.3 \%$ \\
\hline
\end{tabular}

\begin{tabular}{cc}
\hline Freidman test & $.001^{*}$ \\
\hline Pre - 6 m & $0.014^{*}$ \\
\hline Pre - 1 y & $0.016^{*}$ \\
\hline $6 \mathrm{~m}-1 \mathrm{y}$ & 0.157 \\
\hline
\end{tabular}

*p is significant at $5 \%$

TABLE (4) Comparison of frequencies (\%) of joint sounds between observation times

\begin{tabular}{cccc}
\hline \multirow{2}{*}{$\begin{array}{c}\text { Pre- } \\
\text { operative }\end{array}$} & $\begin{array}{c}\text { No sound } \\
\text { Popping clicking } \\
\text { Crepitation }\end{array}$ & 7 & $100 \%$ \\
\hline \multirow{2}{*}{6 months } & No sound & 5 & $71.4 \%$ \\
\cline { 2 - 4 } & Popping clicking & 2 & $28.6 \%$ \\
\hline \multirow{2}{*}{1 year } & No sound & 6 & $85.7 \%$ \\
\cline { 2 - 4 } & clicking & 1 & 14.3 \\
\hline Cochran's Q test & \multicolumn{2}{c}{$.006^{*}$} \\
\hline & Pre - $6 \mathrm{~m}$ & \multicolumn{2}{c}{$<0.037^{*}$} \\
\hline & Pre - $1 \mathrm{y}$ & \multicolumn{2}{c}{$0.008^{*}$} \\
\hline & $6 \mathrm{~m}-1 \mathrm{y}$ & \multicolumn{2}{c}{1.00} \\
\hline
\end{tabular}

*p is significant at $5 \%$

Comparison of frequency (\%) of disc position and morphology between observation times is presented in table 5. Disc position and morphology significantly improved after one year compared to preoperative measurements $(\mathrm{P}=.011)$. Comparison of frequency $(\%)$ of synovial fluid effusion between observation times is presented in table 6. Synovial fluid effusion significantly reduced after one year compared to preoperative measurements $(\mathrm{p}=.013)$.

\section{Patient based outcomes}

Comparison of mean degree of Pain (using VAS) between observation times is presented in table 7 . There was a significant difference in mean degree of Pain (using VAS) between observation times $(\mathrm{p}<.001)$. Mean degree of Pain significantly decreased at 6 months and one year compared to preoperative measurements. Also mean degree of Pain significantly decreased after one year compared to 6 months. Comparison of frequencies (\%) of Pain effect on life between observation times is presented in table 8 . There was a significant difference in frequencies (\%) of Pain effect on life between observation times $(\mathrm{p}=.001)$. Pain effect on life significantly decreased at 6 months and one year compared to preoperative measurements. However, no significant difference in Pain effect on life between 6 months and one year was observed.

TABLE (5) Comparison of frequency (\%) of disc position and morphology between observation times

\begin{tabular}{|c|c|c|c|}
\hline & & Frequency & Percentage \\
\hline \multirow{3}{*}{ 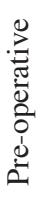 } & Normal & 0 & $0 \%$ \\
\hline & ADD/normal shape & 5 & $71.4 \%$ \\
\hline & ADD/abnormal shape & 2 & $28.6 \%$ \\
\hline \multirow{3}{*}{ 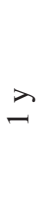 } & Normal & 6 & $85.7 \%$ \\
\hline & ADD/normal shape & 1 & $14.3 \%$ \\
\hline & ADD/abnormal shape & 0 & $0 \%$ \\
\hline
\end{tabular}

Wilcoxon signed ranks test $\quad .011^{*}$

*p is significant at 5\% 
TABLE (6) Comparison of frequency (\%) of synovial fluid effusion between observation times

\begin{tabular}{cccc}
\hline & & Frequency & Percentage \\
\hline \multirow{2}{*}{ Pre-operative } & No effusion & 0 & $0 \%$ \\
\cline { 2 - 4 } & Effusion & 7 & $100 \%$ \\
\hline \multirow{2}{*}{1 y } & No effusion & 6 & $85.7 \%$ \\
\cline { 2 - 4 } & Effusion & 1 & $14.3 \%$ \\
\hline
\end{tabular}

McNamar test $.013^{*}$

*p is significant at $5 \%$

TABLE (7) Comparison of mean degree of Pain (using VAS) between observation times

\begin{tabular}{ccc}
\hline & X & SD \\
\hline Pre-operative & 90.52 & 8.65 \\
\hline 6 months & 30.55 & 5.87 \\
\hline 1 year & 10.18 & 2.64 \\
\hline Repeated measures ANOVA & \multicolumn{2}{c}{$<.001^{*}$} \\
\hline Pre-6 m & \multicolumn{2}{c}{$<.001^{*}$} \\
\hline Pre - 1 y & $<.001^{*}$ \\
\hline $6 \mathrm{~m}-1 \mathrm{y}$ & $.001^{*}$ \\
\hline
\end{tabular}

*p is significant at $5 \%$

TABLE (8) Comparison of frequencies (\%) of Pain effect on life between observation times

\begin{tabular}{|c|c|c|c|}
\hline \multirow{3}{*}{$\begin{array}{c}\text { Pre- } \\
\text { operative }\end{array}$} & & \multirow{2}{*}{$\frac{\text { Frequency }}{2}$} & \multirow{2}{*}{$\frac{\text { Percentage }}{28.6 \%}$} \\
\hline & Not function at all & & \\
\hline & Severe effect & 5 & $71.4 \%$ \\
\hline \multirow{3}{*}{6 months } & No effect & 5 & $71.4 \%$ \\
\hline & Mild effect & 1 & $14.3 \%$ \\
\hline & Moderate & 1 & $14.3 \%$ \\
\hline \multirow{2}{*}{1 year } & No effect & 6 & $85.7 \%$ \\
\hline & Mild effect & 1 & $14.3 \%$ \\
\hline \multicolumn{2}{|c|}{ Freidman test } & \multicolumn{2}{|c|}{$.001 *$} \\
\hline \multicolumn{2}{|r|}{ Pre $-6 m$} & \multicolumn{2}{|c|}{$0.015^{*}$} \\
\hline \multicolumn{2}{|r|}{ Pre -1 y } & \multicolumn{2}{|c|}{$0.015^{*}$} \\
\hline \multicolumn{2}{|r|}{$6 m-1 y$} & \multicolumn{2}{|c|}{0.317} \\
\hline
\end{tabular}

${ }^{*} p$ is significant at $5 \%$

\section{DISCUSSION}

TMJ surgery is indicated for patients who do not respond to conservative treatment and had psychological distress, sleep problems, upregulation of the serotonergic pathway, and pain amplification..$^{20}$ Several surgical techniques have been proposed for management of ID such as condyloplasty (high condylar shave), disk repositioning procedures (discopexy and meniscoraphy), menisectomy, condylectomy, and eminectomy). Discopexy consisted of disk repositioning over the head of the condyle using either mini- anchors ${ }^{21}$ or by suturing technique (meniscoraphy), ${ }^{22}$ thus enhancing normal movement of the joint structures ${ }^{23}$. The aim of discopexy is to reposition the disc in functional position over the condyle ${ }^{24}$, thus reducing disc degeneration by prevention of interference with joint structures and enhancement of normal range of movement ${ }^{25}$ with reduced complications than discectomy ${ }^{26}$

Open joint surgery was used in this study as it has been reported that open surgery is superior to arthroscopic technique in pain reduction in patients with internal derangement (ID) ${ }^{11,14,27}$. Although arthroscopic disc repositioning with a suturing technique is minimally invasive, well tolerated, and has reduced $\operatorname{costs}^{28}$, it may cause long-term joint damage due to degenerative changes ${ }^{29}$. Moreover, this technique is effective in patients without severe deformation ${ }^{26}$. However, it is difficult to perform disk repositioning arthroscopically for severely deformed discs. Consequently, disc surgery was used in this study rather than arthroscopic disc repositioning to eliminate adhesions ${ }^{30}$, and correct severely deformed discs ${ }^{31,32}$

The superiority of a specific surgical technique to another still needed to be to be determined. Moreover, the efficacy of combination of two techniques together in treatment of ID still need further investigation. Accordingly, this study investigated in clinical, radiographic, and patientbased outcomes of high condylar shave with meniscoraphy in the treatment of ID of TMJ. 
The included patients in this study were predominantly females as the vast majority of patients affected by interdental arrangements progressing to surgery are females ${ }^{33}$. It has been reported that Biological, psychological, and social association exists between internal derangement and female gender. $^{34,35}$ Magnetic resonance Imaging (MRI scans) was used for radiographic evaluation of TMJ as it had been considered the main imaging tool for diagnosis and follow-up of TMJ disorders, as it is considered the golden standard in diagnosing TMD, especially when a surgical intervention is consid$\operatorname{ered}^{36}$. MRI provides a much higher soft tissue contrast and can clearly show the normal and abnormal meniscus positions. Excellent resolution of MRI permits detection of abnormal meniscal formation, location, the posterior attachment and the musculature. A recent study ${ }^{37}$ showed the sensitivity of MRI in detection of internal derangement and the authors in this study concluded that TMJ analysis in the sagittal and coronal plane allows to distinguish the correct disc position from disc displacement and thus improve evaluation of TMJ internal derangement.

The high condylar shave with meniscoraphy improved clinical outcome of all tested parameters after surgery compared to preoperative measurements. Maximum mouth opening and lateral movements significantly increased after six months and one year compared to preoperative measurement. This result agreed with the finding of a previous study $^{38}$ in which the authors reported significant improvement of maximum incisal opening compared to average preoperative incisal opening after performing Walker repair (high condylar shave) with disc repositioning. This could be attributed to the increase in joint space and the attachment of the disc to the head of the condyle. The authors concluded that, Walker repair is a viable and predictable treatment option for decreasing pain and increasing incisal opening for participants with $\mathrm{ID}^{38}$ with overall success rate of $86 \%$. Additionally, disc repositioning and suturing was reported to improve mobility of the TMJ significantly during the 6 months after surgery ${ }^{30}$. The improvement of the maximum mouth opening could be attributed to the meniscoraphy with proper disc repositioning and suturing. In line with this explanation, a recent systematic review and meta-analysis ${ }^{12}$ reported $10 \mathrm{~mm}$ overall increased of maximum mouth opening after TMJ surgery with discopexy. However, the authors reported that maximum mouth opening was higher after arthroscopic disc repositioning than open surgery with disc repositioning and suturing. The improvement in lateral movements contrasts the results of other studies ${ }^{22}$, 39 in which the authors reported increased lateral movement using arthroscopic disc repositioning, without improvement after open-joint procedure ${ }^{12}$.

Deviation towards the affected joint, TMJ tenderness, joint sounds significantly decreased after six months and one year compared to preoperative measurement, this is due to decompression of the meniscus, proper positioning and movement of articular components of the joint with no pressure on retrodiscal tissues. The reduction of the deviation toward the affected joint was in line with Griffitts et al. ${ }^{38}$ who reported also that $90 \%$ of patients treated with high condylar shave and disc repositioning has excellent results regarding the range of mandibular movement. The authors added that high condylar shave and disc repositioning technique had marked improvement in TMJ tenderness and JMJ sounds as tinnitus (69\% improved), and crepitus (66\% improved).

After high condylar shave and disc repositioning and suturing, disc position and morphology significantly improved, and synovial fluid effusion significantly reduced after one year compared to preoperative measurements, this is due to decompression of the meniscus and elimination of pressure on the disk during joint movement that is obtained by freeing movement, proper positioning , and securing of meniscus to lateral capsular tissues with no straining or herniation of retrodiscal tissues. A similar observation was noted for MRI analysis of the affected joints in another study ${ }^{40}$ in which the authors found that $89 \%$ of patients submitted 
to open-joint procedure with disc repositioning and suturing after open joint surgery had an appropriate disc-condyle relationship after 5 years of surgery ${ }^{40}$. In line with these results, another short-term result reported increased posterior and superior spaces of the affected joints with changes in the position of the condyles from posterior position to anterior position after an arthroscopic disc repositioning and suturing technique $\mathrm{e}^{41,42}$

Regarding patient-based outcomes, the mean degree of Pain and effect of pain on life significantly decreased at 6 months and one year compared to preoperative measurements, this is due to elimination of pressure on retro discal tissues with proper poisoning of meniscus in relation to articular surfaces, and decrease of inflammation inside joint as capsulitis, synovitis, retro discitis, in addition to decrease of muscular pain comes from muscle splinting as that of lateral pterygoid muscle. The reduction of pain after high condylar shave with meniscus reduction was in agreement with the results of a previous study ${ }^{38}$ in which the authors reported statistically significant decrease in pain by an average of 5.6 points on a scale of 0 to 10 . Explanation of reduction of pain may be due to high condylar shave provide space for the articular disc to function normally. Moreover, the disc repositioning and suturing was reported, in a recent systematic review and meta analysis ${ }^{12}$, to be associated with significant decrease in degree of pain on Visual Analogue scale. The author also reported no significant difference in pain intensity following disc repositioning with either arthroscopic or open joint surgery and suturing. The disc repositioning between articular fossa and the head of condyle with suturing (meniscoraphy) improve acute pain, enhance tissue regeneration, and improve mechanical conditions ${ }^{22}$. In line with our finding, Mercuri et $\mathrm{al}^{43}$ noted significant pain reduction in subjects with meniscus repair and condyloplasty/ eminectomy.

The study limitations include small patient sample. Moreover, Comparison of disc repositioning and suturing between (meniscoraphy) and stabilization of the disc using titanium anchors (discopexy) should be investigated in future studies, as it has been reported that retrodiscal tissues can give the same amount of disk stabilization provided by the rigidity of titanium screws ${ }^{23,44}$

\section{CONCLUSION}

Within the limitation of this study, high condylar shave with meniscorhaphy is an effective treatment of internal derangement of TMJ in cases which did not respond to conservative treatment as it improved clinical, radiographic, and patient-based outcomes.

\section{REFERENCES}

1. Manfredini D, Guarda-Nardini L, Winocur E, Piccotti F, Ahlberg J, Lobbezoo F. Research diagnostic criteria for temporomandibular disorders: a systematic review of axis I epidemiologic findings. Oral Surg Oral Med Oral Pathol Oral Radiol Endod. 2011;112:453-62.

2. Ferendiuk E, Zajdel K, Pihut M. Incidence of otolaryngological symptoms in patients with temporomandibular joint dysfunctions. Biomed Res Int. 2014;2014:824684.

3. Bitiniene D, Zamaliauskiene R, Kubilius R, Leketas M, Gailius T, Smirnovaite K. Quality of life in patients with temporomandibular disorders. A systematic review. Stomatologija. 2018;20:3-9.

4. Walker RV, Kalamchi S. A surgical technique for management of internal derangement of the temporomandibular joint. J Oral Maxillofac Surg. 1987;45:299-305.

5. McCarty WL, Farrar WB. Surgery for internal derangements of the temporomandibular joint. J Prosthet Dent. 1979;42:191-6.

6. Williamson RA, McNamara D, McAuliffe W. True eminectomy for internal derangement of the temporomandibular joint. Br J Oral Maxillofac Surg. 2000;38:554-60.

7. Buckley MJ, Merrill RG, Braun TW. Surgical management of internal derangement of the temporomandibular joint. J Oral Maxillofac Surg. 1993;51:20-7.

8. Eriksson L, Westesson PL. Temporomandibular joint diskectomy. No positive effect of temporary silicone implant in a 5-year follow-up. Oral Surg Oral Med Oral Pathol. 1992;74:259-72. 
9. Gundlach KK. Long-term results following surgical treatment of internal derangement of the temporomandibular joint. J Craniomaxillofac Surg. 1990;18:206-9.

10. Trumpy IG, Lyberg T. Surgical treatment of internal derangement of the temporomandibular joint: long-term evaluation of three techniques. J Oral Maxillofac Surg. 1995;53:740-6; discussion 6-7.

11. Al-Baghdadi M, Durham J, Araujo-Soares V, Robalino S, Errington L, Steele J. TMJ Disc Displacement without Reduction Management: A Systematic Review. J Dent Res. 2014;93:37S-51S.

12. Santos TS, Pagotto LEC, Santos Nascimento E, Rezende da Cunha L, Serra Cassano D, Goncalves JR. Effectiveness of disk repositioning and suturing comparing openjoint versus arthroscopic techniques: a systematic review and meta-analysis. Oral Surg Oral Med Oral Pathol Oral Radiol. 2021;132:506-13.

13. Eppley BL, Delfino JJ. Surgical treatment of internal derangements of the temporomandibular joint: evaluation of two techniques. J Oral Maxillofac Surg. 1988;46:721-6.

14. Al-Moraissi EA. Open versus arthroscopic surgery for the management of internal derangement of the temporomandibular joint: a meta-analysis of the literature. Int J Oral Maxillofac Surg. 2015;44:763-70.

15. Manfredini D. No significant differences between conservative interventions and surgical interventions for TMJ disc displacement without reduction. Evid Based Dent. 2014;15:90-1.

16. Kurita K, Westesson PL, Eriksson L, Sternby NH. High condylar shave of the temporomandibular joint with preservation of the articular soft tissue cover: an experimental study on rabbits. Oral Surg Oral Med Oral Pathol. 1990;69:10-4.

17. Weinberg S. Eminectomy and meniscorhaphy for internal derangements of the temporomandibular joint. Rationale and operative technique. Oral Surg Oral Med Oral Pathol. 1984;57:241-9.

18. American Association of Oral and Maxillofacial Surgery. Criteria for TMJ meniscus Surgery. Chicago AAOMS 1984;32:314.

19. Dingman RO, Grabb WC. Intracapsular temporomandibular joint arthroplasty. Plast Reconstr Surg. 1966;38:179-85.

20. Maisa Soares G, Rizzatti-Barbosa CM. Chronicity factors of temporomandibular disorders: a critical review of the literature. Braz Oral Res. 2015;29.
21. Ruiz Valero CA, Marroquin Morales CA, Jimenez Alvarez JA, Gomez Sarmiento JE, Vallejo A. Temporomandibular joint meniscopexy with Mitek mini anchors. J Oral Maxillofac Surg. 2011;69:2739-45.

22. Goizueta Adame CC, Munoz-Guerra MF. The posterior double pass suture in repositioning of the temporomandibular disc during arthroscopic surgery: a report of 16 cases. J Craniomaxillofac Surg. 2012;40:86-91 .

23. Ryba FM, Ali A, Matthews NS. Temporomandibular joint meniscopexy using the Arthrex Corkscrew(R) mini anchor system: technical note. Br J Oral Maxillofac Surg. 2015;53:299-300.

24. Martin-Granizo R, Millon-Cruz A. Discopexy using resorbable pins in temporomandibular joint arthroscopy: Clinical and magnetic resonance imaging medium-term results. J Craniomaxillofac Surg. 2016;44:479-86.

25. He D, Yang C, Zhang S, Wilson JJ. Modified temporomandibular joint disc repositioning with miniscrew anchor: part I--surgical technique. J Oral Maxillofac Surg. 2015;73:47 e1-9.

26. Hoffman D, Puig L. Complications of TMJ surgery. Oral Maxillofac Surg Clin North Am. 2015;27:109-24.

27. Freeman R. Moderate evidence support a relationship between sugar intake and dental caries. Evid Based Dent. 2014;15:98-9.

28. O'Connor RC, Fawthrop F, Salha R, Sidebottom AJ. Management of the temporomandibular joint in inflammatory arthritis: Involvement of surgical procedures. Eur J Rheumatol. 2017;4:151-6.

29. Abramowicz S, Dolwick MF. 20-year follow-up study of disc repositioning surgery for temporomandibular joint internal derangement. J Oral Maxillofac Surg. 2010; 68:239-42.

30. Sharma R, Sinha R, Menon PS. Meniscopexy for internal derangement of temporomandibular joint. J Maxillofac Oral Surg. 2010;9:261-5.

31. Capan N, Esmaeilzadeh S, Karan A, Diracoglu D, Emekli U, Yildiz A et al. Effect of an early supervised rehabilitation programme compared with home-based exercise after temporomandibular joint condylar discopexy: a randomized controlled trial. Int J Oral Maxillofac Surg. 2017;46:314-21.

32. Tzanidakis K, Sidebottom AJ. Outcomes of open temporomandibular joint surgery following failure to improve after arthroscopy: is there an algorithm for success? Br J Oral Maxillofac Surg. 2013;51:818-21. 
33. Tanaka E, Detamore MS, Mercuri LG. Degenerative disorders of the temporomandibular joint: etiology, diagnosis, and treatment. J Dent Res. 2008;87:296-307.

34. Huang GJ, LeResche L, Critchlow CW, Martin MD, Drangsholt MT. Risk factors for diagnostic subgroups of painful temporomandibular disorders (TMD). J Dent Res. 2002;81:284-8.

35. Bueno CH, Pereira DD, Pattussi MP, Grossi PK, Grossi ML. Gender differences in temporomandibular disorders in adult populational studies: A systematic review and meta-analysis. J Oral Rehabil. 2018;45:720-9.

36. Dolwick MF. Temporomandibular joint surgery for internal derangement. Dent Clin North Am. 2007;51:195-208, vii-viii.

37. Litko-Rola M, Szkutnik J, Rozylo-Kalinowska I. The importance of multisection sagittal and coronal magnetic resonance imaging evaluation in the assessment of temporomandibular joint disc position. Clin Oral Investig. 2021;25:159-68.

38. Griffitts TM, Collins CP, Collins PC, Beirne OR. Walker repair of the temporomandibular joint: a retrospective evaluation of 117 patients. J Oral Maxillofac Surg. 2007;65:1958-62.
39. Hall HD, Indresano AT, Kirk WS, Dietrich MS. Prospective multicenter comparison of 4 temporomandibular joint operations. J Oral Maxillofac Surg. 2005;63:1174-9.

40. Zhang S, Liu X, Yang X, Yang C, Chen M, Haddad MS et al. Temporomandibular joint disc repositioning using bone anchors: an immediate post surgical evaluation by magnetic resonance imaging. BMC Musculoskelet Disord. 2010;11:262.

41. Zhang SY, Liu XM, Yang C, Cai XY, Chen MJ, Haddad MS et al. New arthroscopic disc repositioning and suturing technique for treating internal derangement of the temporomandibular joint: part II--magnetic resonance imaging evaluation. J Oral Maxillofac Surg. 2010;68:1813-7.

42. Hu YK, Abdelrehem A, Yang C, Cai XY, Xie QY, Sah MK. Changes in temporomandibular joint spaces after arthroscopic disc repositioning: a self-control study. Sci Rep. 2017;7:45513.

43. Mercuri LG, Campbell RL, Shamaskin RG. Intra-articular meniscus dysfunction surgery. A preliminary report. Oral Surg Oral Med Oral Pathol. 1982;54:613-21.

44. Rajkumar K, Mukhopadhyay P, Sinha R. Temporomandibular Joint Disc Repositioning Using an Orthopedic Suture Anchor: A Modified Disc Anchoring Technique. J Maxillofac Oral Surg. 2016;15:404-7. 